\title{
Religião e educação na Assembleia Constituinte de 1934: congruências entre o pensamento eugênico e a defesa do ensino religioso*
}

\section{Religion and education in the Constituent Assembly of 1934: congruences between eugenic thinking and the defense of religious teaching}

\section{Religión y educación en la Asamblea Constituyente de 1934: Congruencias entre el pensamiento eugenés y la defensa de la enseñanza religiosa}

\author{
Rafael de Souza Oliveira** \\ Marcelo Furlin***
}

\begin{abstract}
RESUMO
O objetivo deste artigo é mostrar a congruência entre a pauta eugênica e a defesa do ensino religioso na Assembleia Constituinte de 1934. Para tal fim, abordar-se-ão algumas considerações sobre o movimento eugênico no contexto do início da década de 1930 e sua influência sobre o discurso político de aperfeiçoamento moral da sociedade. Verifica-se que o aperfeiçoamento moral é um ideal eugênico congruente com a grande pauta de regeneração moral da sociedade, tendo o ensino religioso com uma importante ferramenta para alcançar tal fim. Por fim, aponta-se para a importância de estudos que se voltem ao passado em busca de reflexões que fortaleçam a democracia brasileira atualmente.

Palavras-chave: Educação; ensino religioso; eugenismo; Constituinte de 1934.
\end{abstract}

\begin{abstract}
The aim of this article is to unfold the congruence between the eugenic agenda and the defense of religious teaching in the Constituent Assembly of 1934. To this end, some considerations about the eugenic movement in the context of the early 1930s and their influence on the political discourse of moral improvement of society will be made. It turns out that moral improvement is an eugenic ideal congruent with the great pattern of moral regeneration of society, with religious teaching as an important tool to achieve this end.
\end{abstract}

* O presente artigo se origina da tese de doutoramento de Rafael de Souza Oliveira intitulada Para Salvar a Nação: uma teorização sobre educação, saúde e religião na Assembleia Constituinte de 1934, desenvolvida sob orientação da Profa. Dra. Roseli Fischmann e Coorientação do Prof. Dr. Marcelo Furlin. Tese disponível em <http://tede.metodista.br/jspui/bitstream/tede/1787/2/Rafael\%20de $\% 20$ Souza $\% 20$ Oliveira.pdf $>$.

** Doutor e mestre em Educação pela Universidade Metodista de São Paulo (UMESP). E-mail: rafaeldsoliveira@gmail.com.

***Doutor em Letras pela Universidade de São Paulo (USP). Coordenador do Programa de Pós-Graduação em Educação da Universidade Metodista de São Paulo (UMESP). E-mail: marcelo.furlin@metodista.br. 
Finally, it is pointed out to the importance of studies that go back to the past in search of reflections that strengthen Brazilian democracy today.

Keywords: Education; religious teaching; eugenism. 1934 Constituent.

\section{RESUMEN}

El objetivo de este artículo es mostrar la congruencia entre la pauta eugenésica y la defensa de la enseñanza religiosa en la Asamblea Constituyente de 1934. A tal fin, se abordarán algunas consideraciones sobre el movimiento eugenésico en el contexto del inicio de la década de 1930 y su influencia sobre el discurso político de perfeccionamiento moral de la sociedad. Se verifica que el perfeccionamiento moral es un ideal eugenésico congruente con la gran pauta de regeneración moral de la sociedad, teniendo la enseñanza religiosa con una importante herramienta para alcanzar tal fin. Por último, se apunta a la importancia de estudios que se vuelvan al pasado en busca de reflexiones que fortalezcan la democracia brasileña actualmente.

Palabras clave: Educación; enseñanza religiosa; eugenesia; Constituyente de 1934.

\section{Considerações iniciais}

A Igreja Católica Apostólica Romana, ${ }^{1}$ no início da década de 1930, está claramente decidida a recuperar seu espaço no poder, após o estabelecimento da separação entre Igreja e Estado, em janeiro de 1890. A luta da Igreja pelo retorno à sua posição privilegiada tomou vulto na década de 1920, período conhecido como Renascimento Católico, quando a instituição retomou um discurso de luta pelos direitos da "maioria" dos habitantes do país - povo católico. Nesse sentido, "a religião da grande maioria dos brasileiros deveria reconquistar um status privilegiado, semelhante à situação no período imperial, em que a religião católica era a oficial do Estado" (WERNET, 2007, p. 15).

Com uma estratégia de demonstração de força e proximidade ao Estado, as autoridades da Igreja conseguem sensibilizar o governo para sua importância e poder de influência no seio da sociedade. Assim, a Igreja consegue, por exemplo, a assinatura do Decreto-Lei de 30 de abril de 1931, que permitia a ela o ensino da religião nas escolas públicas. Mas os planos eram mais ambiciosos. A realização de uma Constituinte representava a oportunidade de readequar a Carta Magna aos interesses da Igreja. Nesse sentido, Dom Sebastião Leme, Cardeal Arcebispo do Rio de Janeiro, coordenou a elaboração de uma medida de muito sucesso: a Liga Eleitoral Católica (LEC).

O mecanismo de ação da LEC consistia em mobilizar o eleitorado católico em todas as dioceses do país para que apoiassem os candidatos comprometidos com a doutrina social da Igreja nas eleições de 1933 para a Assembleia Nacional Constituinte e de 1934 para a Câmara Federal, além das assembleias constituintes estaduais. A LEC atuou ainda nas eleições presidenciais de 1945, nas eleições para a Assembleia Constituinte de 1946 e nas eleições presidenciais de 1950. Em 1962, passou a denominar-se Aliança Eleitoral pela Família (Alef).

\footnotetext{
Doravante denominada Igreja.
} 
As principais medidas propostas pela LEC eram: a promulgação da Constituição em nome de Deus; o reconhecimento constitucional da indissolubilidade do matrimônio e da validade civil do casamento religioso; a adoção da instrução religiosa obrigatória nas escolas públicas de nível primário e secundário; e a concessão de assistência religiosa oficial às forças armadas, às prisões e aos hospitais. Esses três últimos itens constituíam o "programa mínimo" - exigência mínima para que a LEC conferisse seu apoio aos diferentes partidos e candidatos. Questão religiosa é o conceito amplamente utilizado no espaço da Constituinte de 1934 para se referir ao conjunto de propostas defendidas pela Igreja Católica. Tais reivindicações foram integralmente incluídas no texto constitucional. Na opinião de Simon Schwartzman (1986, p. 119), o ensino religioso nas escolas públicas era talvez o mais importante elemento dessa pauta.

O objetivo deste artigo é mostrar a congruência entre uma pauta eugênica e da defesa do ensino religioso na Assembleia Constituinte de 1934. Para tal fim, abordar-se-ão algumas considerações sobre o movimento eugênico no contexto do início da década de 1930 e sua influência sobre o discurso político de aperfeiçoamento moral da sociedade. A pesquisa que origina este artigo analisou os Anais da Constituinte de 1934 por meio de uma abordagem metodológica denominada Grounded Theory. ${ }^{2}$

\section{O movimento eugênico no contexto da Constituinte de 1934}

A história do eugenismo, a ciência do aprimoramento racial, aponta para sua inserção no Brasil no contexto de um entusiasmo generalizado pela ciência como sinal de modernidade cultural. A reduzida elite e a classe médica em expansão eram atraídas por esse pensamento, pela confiança no poder da ciência para criar ordem e progresso e resolver o problema da composição racial do país.

O Brasil foi o primeiro país da América Latina a ter um movimento eugênico organizado, com a fundação, em 1918, da primeira sociedade eugênica brasileira, apenas dez anos depois da sociedade britânica equivalente e seis anos após a francesa. Nessa moldura, Nancy Stepan (2004, p. 333) sugere que os cientistas brasileiros estavam bem sintonizados com os desenvolvimentos científicos europeus. Essa autora avalia, no entanto, que há mais elementos internos do que externos, que teriam influenciado a expansão do eugenismo no país. Segundo ela, a entrada do Brasil na guerra, em 1918, desperta para a possibilidade de prospecção do país no cenário mundial. Destarte, a eugenia aponta para uma possibilidade de regeneração

2 Sobre essa abordagem metodológica, ver: OLIVEIRA (2018), especialmente os capítulos dois e três. 
nacional, atendendo às reivindicações patrióticas e aos anseios de maior visibilidade internacional.

Ademais, a eugenia surgiu no Brasil como resposta ao que era conhecido na década de 1920 como "questão social". A abolição da escravidão, 30 anos antes, sem políticas de inclusão social, a fuga do campo para as cidades e as intensas ondas imigratórias geraram uma massa populacional marcada por intensa miséria e enfermidades. Além disso, as precárias condições de trabalho geraram uma grande greve em 1917, que foi abafada com o uso da força e truculência das polícias e milícias dos governos estaduais e municipais.

A luta para superar a questão social no Brasil coloca em xeque a atitude clássica do liberalismo de laissez-faire frente a essa situação, o que gerou uma séria ameaça de violência urbana. Assim, assume-se a importância do Estado na intermediação de uma relação mais harmoniosa entre trabalhadores e empregadores. A eugenia brasileira associou-se à mobilização pela introdução de uma legislação de bem-estar social como forma de aprimorar o povo brasileiro (STEPAN, 2004, p. 337).

Outro fator, na concepção de Stepan, para a ascensão da eugenia foi o estágio em que a ciência brasileira se encontrava. A Europa, havia muito, simbolizava no imaginário brasileiro tudo o que era civilizado e o avanço do progresso naquele continente esteve associado ao eugenismo. Portanto, uma classe médica em expansão e com ânsia de promover um papel de especialistas na conformação da vida social foi atraída por essa corrente de pensamento, nutrindo um ingênuo otimismo sobre sua própria capacidade de fazer o bem: "Era um grupo pouco afeito a análises revolucionárias das raízes raciais e econômicas das misérias sociais brasileiras" (STEPAN, 2004, p. 337-338).

Por fim, a autora apresenta mais um elemento que teria contribuído para a ascensão da eugenia no Brasil: a crise de identidade racial do país. Raça e relações raciais eram aspectos centrais da realidade social e dos debates ideológicos sobre a capacidade brasileira e o destino nacional. Como nação culturalmente dependente, o Brasil era fortemente influenciado pelas ideias raciais da Europa, da França em especial. Assim, interpretações racistas do Brasil vindas do exterior causavam dúvidas quanto à identidade racial do país. Em suma, essas interpretações assumiam que cruzamentos promíscuos que tinham ocorrido no Brasil desde os tempos coloniais até aquele momento haviam produzido um povo degenerado, instável, incapaz de desenvolvimento progressivo. Muitos entre a elite brasileira compartilhavam desse ponto de vista (STEPAN, 2004, p. 338).

Tendo em vista o espaço que as discussões sobre eugenia tomaram globalmente, uma constituinte realizada nesse período histórico seguramente 
seria envolvida por esse intenso debate. O pensamento eugênico na Constituinte de 1934 vai alimentar o sentimento nacionalista marcante nos discursos, recebendo o apoio, por um lado, do higienismo, ${ }^{3}$ como um importante axioma de pensamento em saúde, e, por outro lado, da enorme legitimidade e inserção do discurso religioso na população. $O$ atraso econômico é visto como resultado da ineficiência do brasileiro. Tal problema poderia ser superado, sob a égide eugênica, com o aperfeiçoamento da raça, que se daria, no contexto dos debates constituintes, para a tentativa de solução de dois grandes problemas nacionais: saúde e educação.

A preocupação eugênica de aperfeiçoamento da raça envolve o aperfeiçoamento físico, intelectual e moral. O aperfeiçoamento físico é um conceito atrelado a diversas motivações que tangem ao aperfeiçoamento para o trabalho, para o exercício militar e o melhoramento racial. Já o aperfeiçoamento intelectual baseia-se na extrema confiança otimista no poder da educação de resolver os problemas do país. O movimento da Escola Nova ${ }^{4}$ teria contribuído para esse sentimento de que bastaria a modernização e racionalização do sistema educacional para que os problemas nacionais começassem a se resolver. Esse conceito significa, assim, a visão da educação como um importante problema social, tendo em vista a ineficiência do homem - causa do atraso econômico.

Além disso, não está dissociado da ideia de melhoramento racial o aperfeiçoamento moral da sociedade. O ideal moral reúne os grupos mais diversos a seu favor. Protestantes, católicos, positivistas, higienistas e eugenistas não questionam a importância da regeneração moral em um projeto de construção nacional. Em um ideal moral laico, parte-se do pressuposto de que moral independe de religião. Nessa concepção, a despeito do ensino religioso, defende-se a obrigatoriedade da Educação Moral e Cívica. O ensi-

\footnotetext{
A Higiene é um ramo da medicina que se ocupou da descrição e redescrição dos objetos sociais em conformidade com os cânones da ciência médica. A inserção do movimento no Brasil se deu a partir do século XIX, como esforços da nova elite urbano-comercial e de intelectuais brasileiros, especialmente da classe médica, amplamente influenciados por ideais europeus de civilização, urbanismo e medicina social, incluídos no grande projeto de organização de um Estado Nacional (GONDRA, 2007, p. 521). Esse movimento, por suas muitas congruências com o eugenismo, fornece-lhe ferramentas para a concretização de seus objetivos, tendo em vista algumas resistências ao eugenismo impostas naquele contexto.

4 Importante aqui fazer um adendo sobre a ressignificação dos educadores católicos à ideologia liberal da Escola Nova, que ganhara força no contexto educacional brasileiro. A pedagogia católica empenhou-se em encontrar um caminho médio entre as concepções tradicionalistas da educação e o ideário da educação nova. Concomitante à crítica, havia um processo crescente de autorreformulação, o que propiciou o desenvolvimento de um escolanovismo católico. Ver: GHIRALDELLI JR., 2009, p. 58-64.
} 
no cívico é um termo presente no Anteprojeto do Governo Provisório. ${ }^{5} \mathrm{O}$ projeto da Comissão dos $26^{6}$ apresenta para votação da plenária a obrigatoriedade da educação moral e cívica. No entanto, o tema vitorioso do embate é o ensino religioso.

\section{Defesa do ensino religioso}

Como já mencionado, o ensino religioso foi talvez o tema mais importante da pauta oficial da Igreja nos debates constituintes. Sua defesa está baseada principalmente em duas linhas. A primeira diz respeito ao ensino religioso como uma aspiração da maioria católica e a segunda, dentro da proposta católica de regeneração moral da sociedade, aponta o ensino religioso como uma grande necessidade do país.

\section{A vontade da maioria}

Quanto à primeira linha, os argumentos utilizados voltam-se para o país como uma grande Nação Católica. Nesse sentido, expressões como país católico, povo católico, maioria da casa, Brasil cristão, entre outras, são utilizadas para justificar o reordenamento religioso da constituição como vontade de uma maioria que poderia ditar as leis a toda a nação. Contrária a essa ideia é a acusação de opressão de liberdade de consciência.

Destarte, o tema da liberdade de consciência assume o centro dos debates acerca da defesa do ensino religioso. De um lado, pela defesa do ensino leigo, ${ }^{7}$ o ensino religioso nas escolas seria imposição do catolicismo sobre outros credos. Por outro, a liberdade de consciência na questão religiosa assume um caráter mais abstrato. Ao mesmo tempo que sua importância é afirmada, pois a "liberdade é um dom de Deus", nega-se sua amplitude, uma vez que "liberdade está perto da licença". Logo, essa liberdade tende a ser relativizada. A única consciência que pode ser livre é aquela disciplinada pela Igreja, daí a importância do ensino religioso.

O discurso católico contrário às acusações de imposição de consciência será baseado na característica de facultatividade do ensino religioso, ou seja,

Trata-se de um projeto de Constituição elaborado pelo Governo Provisório e encaminhado para análise da Constituinte. Acabou se tornando a base para as atividades da comissão que apresentaria a proposta de Constituição a ser votada pela plenária da Assembleia.

6 Comissão responsável por apresentar à plenária da Constituinte um projeto de Constituição. Era formada por um representante de cada bancada estadual e pelos grupos profissionais. Ao todo eram 26 componentes, o que a tornou conhecida como a Comissão dos 26.

7 Termo utilizado naquele contexto. O termo mais utilizado hoje é laico. 
se o ensino é facultativo, não pode ser considerado imposição. Adroaldo Costa $^{8}$ argumenta sobre isso nestes termos:

Tenho para mim que a maioria da Nação Brasileira é católica e que ela, portanto, tem o direito de ditar as leis a toda a Nação, porquê, no regime democrático, e nós vivemos em uma democracia, é a maioria quem governa. Entretanto, repitamo-lo mais uma vez, para que todo aquele que tiver ouvidos ouça, nós não queremos que só os desejos da maioria sejam satisfeitos, senão que os desejos da totalidade o sejam, e, por isso, queremos o ensino da religião, como um direito de uso facultativo e não de obrigação imperativa; queremos o ensino de todas as religiões, de todos os credos: o da religião católica para os católicos; o da de Lutero, para os luteranos; o da de Alan Kardec, para os espiritistas; o da de Maomet, para os seus adeptos, e assim por diante. Poderá haver maior liberdade, maior tolerância, maior respeito à consciência alheia? (ANNAES, p. 196, v. VII)

No entanto, como argumenta Guaraci Silveira, se o ensino religioso fosse realmente facultativo, como previa a legislação, não haveria qualquer manifestação contrária, pois não teria qualquer opressão de consciência. Mas o que ocorreu na realidade, segundo tal constituinte, foi uma imposição do ensino religioso, burlando a lei vigente naquele momento, ${ }^{10}$ conforme trecho a seguir:

O SR. GUARACI SILVEIRA - Durante a interventoria do Dr. Laudo Camargo, em São Paulo, foi regulamentado o ensino religioso nas escólas. Lendo a regulamentação, que era magistral, nenhum protestante teria receio do ensino religioso. Dizia a lei regulamentadora que o ensino seria facultativo; que nenhum professor, na classe, poderia falar em religião; que as aulas religiosas seriam dadas a requerimento dos pais, com firmas reconhecidas; que o ensino seria feito fora do periodo escolar; e que os professores seriam nomeados pelas autoridades eclesiásticas. Bravos, diriamos todos nós. Aí estava uma fórmula que não oprimia a quem quer que fosse.

O SR. BARROS PENTEADO - É, exatamente, o que todos queremos.

O SR. GUARACI SILVEIRA - Pois bem, Senhores. No Estado de São Paulo, alguns dias depois, o que se verificava? Não havia mais necessidade de requerimento; as professoras distribuiam fichas e exigiam dos alunos que trouxessem a resposta.

8 Adroaldo Mesquita da Costa foi eleito, com mais dois constituintes, na legenda da Frente Única Gaúcha (FUG), que fazia oposição no Rio Grande do Sul ao grupo governista que foi apoiado pela LEC e elegeu 13 deputados. No entanto, como católico ultramontano, se inclinava em favor das medidas propostas pela LEC. Isto lhe valeu um considerável número de votos entre eleitores católicos de oposição, e em sua atuação na Constituinte acabou por revelar-se um dos mais constantes defensores das posições da Igreja.

9 Guaraci Silveira nasceu em Franca (SP) em 1893. Ministro da Igreja Metodista, elegeu-se deputado à Assembleia Nacional Constituinte por São Paulo, na legenda do Partido Socialista. Foi uma das principais vozes na defesa do Estado laico.

10 Trata-se do Decreto n. 19.941, de 30 de abril de 1931, que dispunha sobre a instrução religiosa nos cursos primário, secundário e normal, tornando-a facultativa. 
$[\ldots]$

O SR. GUARACI SILVEIRA - O que é fato é que, as aulas religiosas, contra a lei, passaram a ser dadas na classe pelas professoras (ANNAES, p. 273-274, v. II).

Tal debate fica bem caracterizado no trecho a seguir do discurso de Fernando Magalhães, ${ }^{11}$ em 13 de dezembro de 1933:

O SR. FERNANDO MAGALHÃES - Sinto, portanto, esta disposição muito humana, muito razoável, muito merecedora situação de quem se debate na ansia de compreender e de nós. E é por êsse motivo que, sentindo, chorando e sofrendo as calamidades do Brasil, compreendendo a dificuldade que se entrevê no seu futuro, ameaçado de destruição, como ameaçados de destruição foram aqueles que tiveram depois de chorar nos muros sabáticos, noto que é preciso respeitar a crença de todos - e esta é a minha resposta - sem imposições, que não existem, mais com a simples condição facultativa... O SR. ANTONIO RODRIGUES DE SOUSA - É uma imposição disfarçada.

O SR. FERNANDO MAGALHÃES - A êste aparte de V. Ex. eu não sei responder.

O SR. TOMAZ LÔBO - Porque não pode responder.

O SR. FERNANDO MAGALHÃES - Não posso porque seria obrigado a dizer que a opinião de V.Ex. é também disfarçada.

O SR. TOMAZ LOBO - Perdão; disfarçada, não. Assumo atitudes; defino o meu pensamento. O que desejo é um regime de liberdade.

O SR. FERNANDO MAGALHÃES - Com que intuito? A liberdade está perto da licença.

O SR. TOMAZ LÔBO - V. Ex. está pregando e querendo impor uma religião.

SR. ANTÔNIO RODRIGUES IDE SOUSA - Religião é questão de consciência; não pode ser imposta em hipótese alguma.

O SR. FERNANDO MAGALHÃES - Acabo de afirmar a condição facultativa do dispositivo constitucional.

O SR. ANTÔNIO RODRIGUES DE SOUSA - É imposição disfarçada (ANNAES, p. 285-286, v. II).

Nas tramas dessa linha argumentativa, percebe-se a força de uma ideologia da democracia como vontade da maioria, muito embora seja importante enfatizar o discurso esclarecido de homens além do seu tempo que rechaçam tal ideia, como Guaraci Silveira, para quem o respeito ao direito dos homens é o principal argumento contra a questão religiosa. Para ele, os direitos dos homens devem ser respeitados, logo não precisam constar na constituição. "Incluir os direitos da maioria na Carta Magna seria um veículo de opressão das minorias" (ANNAES, p. 280, v. II).

11 Fernando Augusto Ribeiro Magalhães nasceu no Rio de Janeiro em 1878 e formou-se pela Faculdade de Medicina do Rio de Janeiro em 1899. Foi presidente da Associação Brasileira de Educação para os biênios 1926-1927 e 1930-1931. Foi eleito deputado pelo estado do Rio de Janeiro à Assembleia Nacional Constituinte na legenda do Partido Popular Radical (PPR). 
O SR. GUARACI SILVEIRA - ... dizia que a educação moral e cívica deveria ser matéria obrigatória nas escolas.

O SR. COSTA FERNANDES - Moral? Sem religião, não há moral.

O SR. GUARACI SILVEIRA - Num país que se diz cristão, é obvia a pergunta.

O SR. CORREIA DE OLIVEIRA - O país é católico. A maioria dos brasileiros é católica e a expressão genuina do cristianismo é o catolicismo.

O SR. GUARACl SILVEIRA - Não concordo com V. Ex. Essa maioria vamos ver, daqui a poucos dias, no carnaval (ANNAES, p. 274, v. II)

A segunda linha de defesa do ensino religioso é no campo da moral. Parte-se do pressuposto que a Igreja tem uma missão civilizadora de guiar os povos, "regenerando os costumes do mundo pagão, dignificando a mulher, ensinando a verdade e o bem" (ANNAES, p. 319, v. V). Arruda Câmara, ${ }^{12}$ para ilustrar tal tese, cita as universidades, colégios, hospitais, orfanatos, além de mencionar "os descobrimentos e as invenções, a catequese dos índios e a colaboração na liberdade dos povos". O sacerdote católico, citando Robespierre, ainda destaca a importância do catolicismo para a moralidade dos povos, pois tal culto seria capaz de "deixar nos espíritos dogmas imponentes, que prestam apôio ás ideias morais e á doutrina sublime e tocante da virtude que o Filho de Maria ensinou outróra aos seus concidadãos" (ANNAES, p. 319, v. V). E, ao citar Agostinho, vai defender que a fé cristã, ao invés de ser prejudicial ao Estado, lhe é salutar. Essa contribuição da fé cristã ao Estado por meio da Igreja diz respeito a diversos mecanismos sociais de controle que o discurso religioso é capaz de impor aos fiéis.

"Tu diriges e instrues as crianças com ternura, os adolescentes com energia, os velhos com brandura, como o comporta a idade, não só do corpo, mas também da alma. Submetes as mulheres aos seus maridos, por uma casta e fiel obediência, não para saciar a paixão, mas para propagar a prole e constituir a sociedade da família. Dás autoridade aos maridos sobre as suas mulheres, não para que abusem da fraqueza do seu sexo, mas para seguir as leis do sincero amor. Subordinas os filhos aos pais, por uma espécie de sujeição livre, e dás aos pais autoridade sôbre os filhos para a exercerem com ternura. Unes não sómente em sociedade, mas numa espécie de fraternidade os cidadãos aos cidadãos, as nações ás nações e a humanidade inteira com a lembrança dos primeiros pais. Ensinas aos reis a velar sôbre os povos e prescreves aos povos que se submetam aos reis. Ensinas com esméro a quem é devida a honra, a afeição, o respeito, o temor, a consolação, os conselhos, o estímulo, a correção, a censura, o castigo, e fazes saber

12 Alfredo de Arruda Câmara, sacerdote católico, líder da bancada de Pernambuco, eleito deputado à Constituinte na legenda do Partido Social Democrático (PSD). Como deputado constituinte, restringiu praticamente sua participação ao tratamento dos problemas eclesiásticos. 
como não sendo todas as coisas devidas a todos é devida a todos a caridade e a ninguém a injustiça." E alhures: "Aqueles que dizem que a doutrina de Cristo é contrária ao bem do Estado, dêem-nos um exército de soldados, tais como os faz a doutrina de Cristo, dêem-nos governadores de províncias, pais, filhos, maridos, esposas, senhores, servos, reis, juízes, contribuintes, enfim, recebedores, como os quer a doutrina cristã. E ousem ainda dizer que ela é contrária ao Estado. Mas ao invés não hesitem em confessar que ela é salutar ao Estado, quando observada (carta CXXX, a. Marcelino)" (ANNAES, p. 319, v. V).

Depreende-se do excerto acima que tal colaboração com o Estado se resume em legitimar práticas conservadoras e mantenedoras do status quo como medidas de controle social - patriarcalismo, submissão da mulher, subordinação dos filhos, monogamia indissolúvel -, além de medidas de legitimação política, ou seja, submissão a governos, o que é um importante elemento de repressão a movimentos de questionamento da ordem social.

A indissolubilidade do casamento revela uma afinidade direta com o pensamento eugênico. No discurso de Annes Dias, ${ }^{13}$ por exemplo, há uma citação a Theodore Roosevelt, como notável estadista, que, estudando "os efeitos do divórcio em sua pátria, afirmou que esta marchava para o suicídio da raça”" (ANNAES. p. 202, v. VIII). Tal constituinte também afirma que:

Um dos mais exaltados divorcistas patrícios reconhece textualmente "que a continuidade do matrimônio é um instinto da espécie e que a união por toda a vida é o ideal para o qual deve tender o aperfeiçoamento". Ora, o divórcio afasta dêsse ideal porquê torna instáveis e precários os laços conjugais (ANNAES, p. 203, v. VIII).

Além do mais, a reafirmação de um papel social da mulher segundo preceitos conservadores também interessava aos eugenistas brasileiros, para quem o feminismo significava um sério risco ao tradicional papel reprodutivo da mulher. A eugenia brasileira deu especial ênfase a temas como a saúde materna e o cuidado pré-natal (STEPAN, 2004, p.352).

A defesa da família tradicionalmente constituída é um dos grandes temas da constituinte de 1934. A religião entra como estrutura ideológica para a sacralidade do casamento e sustentadora de ideais morais, dentro de uma perspectiva que parece entender que apenas no arcabouço religioso a família se legitima. Nesse aspecto, a Igreja e liberais se posicionam favoráveis ao casamento monogâmico indissociável. Para eles, isso garante a estabilidade da família e, consequentemente, do Estado.

13 Heitor Annes Dias nasceu em Cruz Alta (RS) em 1884. Bacharelou-se pela Faculdade de Medicina de Porto Alegre em 1905. Em maio de 1933, elegeu-se deputado pelo Rio Grande do Sul à Assembleia Nacional Constituinte, na legenda do Partido Republicano Liberal (PRL). Como deputado constituinte, apresentou proposições contra o divórcio e sobre endemias rurais. 
O divórcio dissolve as famílias e, entre os mais extremados divorcistas se acham os que tentam anular a noção de pátria e destruir a sociedade. Para êsses o divórcio é a primeira conquista necessária, pois a desorganização da família facilitará a da sociedade (ANNAES, p. 204, v. VIII).

Além dessa pauta que representa interesses oficiais da Igreja, é importante destacar uma pauta defendida pelo conservadorismo católico que visa promover uma regeneração moral da sociedade, que vinha, na opinião desse grupo, definhando moralmente nos últimos 40 anos de república na qual a presença da Igreja estivera enfraquecida no cenário público, como se observa no trecho a seguir:

O SR. FERNANDO MAGALHÃES - Nesta hora, ouço uma voz unanime clamar contra quarenta anos de República inútil, que desperdiçou a riqueza e inutilizou a cultura, que preparou doutores sem conta e ensino sem crédito. Pergunto: que foi que preparou esta sociedade desorganizada?

O SR. GUARACI SILVEIRA - Indago do orador: êsses quarenta anos de República destruiram que? Quatrocentos anos de ensino religioso que nada adiantou á Pátria.

O SR. FERNANDO MAGALHÃES - Foram êsses quarenta anos, que culminaram numa revolução...

UM SR. DEPUTADO - Revolução política.

O SR. FERNANDO MAGALHÃES - . . . que se aponta como purificação, que veio resgatar os males reconhecidos por esta Assembleia revolucionária; revolução que se preparou, como consequência fatal da dissolução, da miséria popular, do abandono da Igreja, do esquecimento da palavra divina, do desconhecimento da noção essêncial da Família, quando não se respeita a organização da casa; foram esses quarenta anos da República leiga que aceleraram a catástrofe nacional, culminante na Revolução de 1930 (ANNAES, p. 282, v. II).

A pauta moral do discurso eugênico encontra amparo nesse contexto. A emenda 781 é um texto que revela uma importante relação entre Igreja e eugenia. Essa emenda tem seu conteúdo parcialmente integrado à Carta Constitucional. Sendo assim, sua reprodução na sequência torna-se significativa:

\section{N. 781 \\ Onde convier: \\ CAPÍTULO - ASSISTÊNCIA SOCIAL}

Art. Incumbe á União como aos Estados e aos Municípios, nos termos da lei federal: a) velar pela saúde pública, assegurando o indispensável amparo aos desvalidos, creando serviços especializados e estimulando os serviços sociais cujas finalidades procurará coordenar;

b) incentivar a educação eugênica e sexual; 
c) amparar a maternidade e a infância;

d) socorrer as famílias de prole numerosa;

e) proteger a juventude contra toda exploração, bem como contra o abandono físico, moral e intelectual;

f) adotar medidas legislativas e administrativas tendentes a restringir a mortalidade e a morbicidade infantil;

g) adotar medidas de higiene social, visando impedir a propagação das doenças transmissíveis;

h) cuidar da higiene mental, incentivando a luta contra os venenos sociais.

Parágrafo único. Todos os problemas relativos á saúde e á assistência serão estudados e coordenados por Conselhos Técnicos e pelos órgãos creados visando o aperfeiçoamento da raça.

\section{Justificação}

Não será novidade introduzir na Constituição Brasileira um programa unitário de ação social. A Alemanha, que possue velhas tradições de autonomia local e regional, não hesitou, na Constituição de Weimar, em fazer recair sobre os poderes públicos a obrigatoriedade de cuidar dos problemas sociais, procurando atenuar os sofrimentos consequentes da miséria (assistência paliativa); reconduzir o indivíduo e a família ás condições normais de existência (assistência curativa); prevenir os flagelos sociais (assistência preventiva); melhorar as condições sociais e elevar o nível da existência (assistência construtiva).

País novo, de grande vastidão territorial, de clima variável, com uma população constituída pelas raças mais heterogêneas, de costumes e hábitos diferentes, vivendo nas mais diversas condições higiênicas, não se compreende a razão de se não incluir na nossa magna Carta um Capítulo em que se consubstancie, em linhas gerais, medidas para remediar as necessidades da coletividade, baseadas em dados científicos e racionais. Assim, a educação eugênica se impõe, atendendo a que a eugenia não só tem por fim a procriação em boas condições fisiológicas, como ainda estuda as causas disgenéticas ou as que podem influir direta ou indiretamente sobre o valor da espécie dando a cada cidadão o sentimento da responsabilidade na formação da raça.

A educação sexual é a base da luta antivenérea e é paralela á educação eugênica, de acôrdo com as conclusões da Conferência Internacional para a reafirmação do ideal moral no mundo.

Insistir sôbre a necessidade do Estado amparar a infancia e a maternidade é um truismo nos dias que correm.

Adotar medidas legislativas e administrativas tendentes a restringir a mortalidade e a morbicidade infantil é, de acôrdo com as resoluções da Conferência Nacional de Proteção á Infancia, realizada no Rio de Janeiro em outubro de 1933, um dever indeclinável do Estado.

As medidas de higiene social devem obedecer a uma unidade de ação de forma a dar eficiência á luta contra a verminose, o impaludismo, a tuberculose, a lepra, as doenças venéreas, o cancer.

Convém, outrossim, que figure na Carta Constitucional a expressão do sentimento coletivo que anima os brasileiros da atual geração, dando aos poderes públicos a incumbência de zelar pela higiene mental e combater os vícios sociais sobretudo o alcoolismo. 
Dessa forma, a atual geração afirmará aos pósteros que os mágnos problemas atinentes ao futuro da raça não deixaram de preocupar os que se empenharam na elaboração da Carta Constitucional de 1933.

Sala das Sessões, 16 de Dezembro de 1933. - A. C. Pacheco e Silva. - Carlota P. de Queiroz. - Almeida Camargo. - C. de Mello Neto. - Roberto Simonsen. - A. Siciliano. - Ranulpho Pinheiro Lima. - Abelardo Vergueiro Cesar. - Oscar Rodrigues Alves. - Th. Monteiro de Barros Filho. - Alcantara Machado. - Barros Penteado. - José Ulpiano. - Abreu Sodré. - Cincinato Braga. - Manuel Hyppolito do Rego. - José Carlos de Macedo Soares. - M. Whatelly. - Henrique Bayma. - Horacio Lafer. - C. Moraes Andrade. (ANNAES, p. 175-176, v. IV).

Apreende-se de tal emenda como a ideologia eugênica desenvolveu-se no Brasil, tendo em vista o contexto de reaproximação da Igreja ao centro do poder e o movimento de regeneração moral da sociedade. Nessa conjuntura, eugenizar significa sanear (STEPAN, 2004, p. 345). O propósito geral da emenda está explícito no parágrafo único - "visando o aperfeiçoamento da raça" -, mas as medidas propostas fogem do extremismo observado, por exemplo, no eugenismo nazista, para propor um caminho que tende para os ramos mais higienistas do eugenismo, como a educação eugênica, a puericultura, o combate à mortalidade e à morbicidade infantis, e um tema que tem muito amparo na moralidade católica: o combate ao alcoolismo e outros males sociais. Naquele contexto, esterilização, controle da natalidade e aborto eram percebidos como anticatólicos e continuariam ilegais no Brasil até muito recentemente. O tema aborto ainda hoje representa muitas tensões nos debates políticos e sociais. Mas uma legislação antialcoólica, pauta antiga de eugenistas brasileiros, e o exame pré-nupcial obrigatório obtiveram considerável apoio.

O tema da educação eugênica ${ }^{14}$ assume considerável importância na ideologia eugênica brasileira. Haja vista as limitações impostas pela conjuntura supracitada, a educação eugênica aparece como meio possível de se criar uma cultura eugênica, ou seja, dar a cada cidadão o sentimento da responsabilidade na formação da raça. A emenda 781 vai introduzir a educação eugênica nas incumbências da União, Estados e municípios, já que o anteprojeto apresentado pelo governo provisório não a previa nesses termos. ${ }^{15}$ Embora a Comissão dos 26 tenha tentado retirar a expressão do texto, substituindo-a por 'incentivar a educação', a educação eugênica entra na Carta constitucional, ficando de fora a expressão educação sexual, o que pode representar certas reservas do conservadorismo católico para adotar tal termo. ${ }^{16}$

\footnotetext{
14 O tema é mais amplamente abordado em OLIVEIRA (2018), seção 5.4.3.

15 A emenda 781 é uma reformulação do artigo 110 do Anteprojeto de Constituição apresentado pelo Governo Provisório.

16 A questão do preconceito à educação sexual é um tema que Renato Kehl vai empreender esforços para desfazê-lo, principalmente no trabalho O problema da educação sexual: importancia engênica, falsa com-
} 
Para que a Igreja coloque em prática toda essa potencialidade social, é necessário chegar ao povo. Segundo Schwasrtzmann, o catolicismo no país se caracteriza pelo que se denomina de "catolicismo habitual" ou de fachada, ou seja, as "normas éticas e morais da Igreja eram constantemente violadas, destacando todos em um estado mais ou menos permanente de pecado", situação "compensada pelos ritos de absolvições" (SCHWASRTZMAN, 1986, p. 112). Daí o apoio a um plano Nacional de Educação - cujo projeto educacional já estava sendo disputado pelo grupo de educadores católicos da $\mathrm{ABE}$ - e a universalização do ensino - tendo em vista que a escola pública era para poucos. Mas o primeiro passo no projeto da Igreja seria realmente o ensino religioso.

Cabe ainda o destaque dado ao papel do Estado na fiscalização desse ensino moral. Costa Fernandes ${ }^{17}$ argumenta que, na Polônia, os princípios orientados pela Instrução Pública oferecem um exemplo de vigilância do Estado, pela fiscalização da formação do caráter da mocidade, no cuidado pela elevação do seu nível moral, do desenvolvimento da noção de patriotismo e dos sentimentos religiosos, pois o ensino religioso é obrigatório para todos os alunos nas escolas do país. Nesse sentido, estão as bases da defesa da fiscalização higiênica das escolas ${ }^{18}$ (ANNAES, p. 111, v. V).

O contexto mundial aponta para o fortalecimento de Estados fiscalizadores e autoritários. O eugenismo concorda com esse tema, obviamente por entender que as políticas eugênicas são de obrigação do Estado, o que será inúmeras vezes defendido nos debates. Miguel Couto ${ }^{19}$ é favorável á tese, por exemplo, de que o Estado assuma a tutela de crianças e devolva já educados à suas famílias, tendo em vista a superação de alguns problemas colocados à

preensão e preconceitos - Como, quando e por quem deve ser ministrada, apresentado no I Conferência Nacional de Educação, em 1927. É importante destacar que o "interesse eugênico na educação sexual pouco tinha a ver com visões radicais sobre sexualidade ou papéis sexuais. Pelo contrário, a eugenia brasileira vinculava-se estreitamente a uma ideologia conservadora" (STEPAN, 2004, p.352).

17 Francisco da Costa Fernandes se formou médico pela Faculdade de Medicina de Salvador em 1903. Elegeu-se deputado pelo Maranhão à Assembleia Nacional Constituinte na legenda da União Republicana Maranhense, com o apoio da LEC. A atuação de Costa Fernandes foi marcada pela defesa dos interesses da Igreja representados na questão religiosa. Defende a indissociabilidade entre educação e religião. Sobre esse assunto, ver OLIVEIRA (2018), seção 5.4 .

19 Miguel de Oliveira Couto, médico formado pela Faculdade de Medicina do Rio de Janeiro em 1985. Elegeu-se deputado à Assembleia Nacional Constituinte na legenda do Partido Economista, pelo Distrito Federal. Membro da Comissão de Saúde da Assembleia, interessou-se ainda por duas questões: a educação e a imigração. Na defesa da primeira, afirmava que o único problema nacional era a educação do povo, assertiva utilizada por outros deputados sempre em referência à credibilidade de Miguel Couto. Foi autor da emenda vitoriosa que obrigava o emprego de $10 \%$ da renda federal na instrução pública. Quanto à imigração, liderou a corrente que se opunha à imigração não europeia, desenvolvendo intensa campanha contra a entrada de japoneses no Brasil. 
época: a frequência dos alunos e a disponibilidade de professor nas escolas rurais (ANNAES, p. 449, v. VIII).

Costa Fernandes é um dos grandes defensores do ensino religioso dentro de uma perspectiva moral. Para ele, ao estabelecer o ensino religioso obrigatório, Mussolini estaria defendendo a sociedade e a família, pois elas estariam apoiadas nesses princípios (da religião). O ensino religioso obrigatório elevaria a "moral das almas, condição indispensável para a felicidade de um povo" (ANNAES, p. 111, v. V).

Êste exemplo, dado por um dos homens mais notáveis dêstes ultimos tempos, deve impressionar os povos que desejam salvar-se dos efeitos do ciclone, produzido pelo desequilíbrio econômico do Mundo, ciclone que procura destruir a civilização ocidental, que é uma das mais belas conquistas do Cristianismo (ANNAES, p. 111, v. V).

Para Costa Fernandes, o exemplo de Mussolini deveria inspirar os "povos que desejam salvar-se dos efeitos do ciclone [...] que procura destruir a civilização ocidental". Ciclone deve ser lido como comunismo. $\mathrm{Na}$ visão do constituinte, o comunismo é uma grande ameaça a "uma das mais belas conquistas do Cristianismo" - a sociedade ocidental. De maneira geral, esse entusiasmo por Mussolini era compartilhado entre os eugenistas brasileiros, que admiravam os amplos programas de proteção familiar desenvolvidos por ele na Itália fascista, "programas cuja orientação pró-família, pró-catolicismo, antiabortiva e antifeminista era altamente congruente com a ideologia eugênica brasileira" (STEPAN, 2004, p. 376).

Esse deputado ainda fará uma ligação entre a defesa da moral e o anticomunismo, no sentido de que ser comunista é imoral. Sendo assim, lança mão do discurso do Ministro da Instrução Pública do Japão para defender o ensino religioso, tendo em vista a regeneração moral.

Enquanto no Brasil, país de população católica, alguns espíritos, sob o preconceito de liberdade de consciência, se opõem ao ensino religioso nas escolas, no Japão, onde o sentimento de patriotismo atingiu ao seu mais alto grau, os seus homens justamente impressionados pelo desenvolvimento progressivo da imoralidade naquele país, pela falta de disciplina mental das crianças, pela voz do Ministro da Instrução Pública fiséram o seguinte apêlo ao visitador apostólico, de Tóquio: "Até agora a política de dêste ministério orientou-se pelo materialismo. É a doutrina da época corrente; mas, todos devemos confessar os resultados deploráveis colhidos, a decadência assustadora da moralidade pública e privada, a floração do comunismo; e, nos tempos mais recentes, simptomas graves de rebeldia e de indisciplina social. Chegou, pois, a hora de reconhecermos que o ensino público no Japão tem de se espiritualizar. Para êste fim, a colaboração dos educadores religiosos é-nos absolutamente necessária. É essa colaboração, por meio dos missionários, que eu venho solicitar. Os princípios da religião católica têm de informar, 
doravante, a educação da mocidade escolar, sob pena de abrirmos, de par a par, as portas ao perigo vermelho mais terrível".

Estas palavras do Ministro Japonês devem ser consideradas insuspeitas; e, todos aqueles que se interessam pelo bem da Pátria, não podem deixar de refletir sobre o assunto (ANNAES, p. 108, v. V).

O discurso anticomunista é um importante veio de aproximação entre religiosos e eugenistas, além, obviamente, de ser benquisto pelo governo. $\mathrm{O}$ ensino religioso nas escolas, por exemplo, é defendido pelo grupo eugenistas como meio de equilibrar a questão imigratória, considerando-se o risco de importação desses ideais com os imigrantes europeus. No ponto de vista da Igreja, segundo Eduardo Góes de Castro (2007, p. 23), "preocupava aos religiosos a ação dos anarquistas e comunistas que, atuando no meio operário, aliciava os trabalhadores das bases católicas".

Também contribuía para as atitudes anticomunistas a ampla divulgação das mensagens de Nossa Senhora por ocasião de sua aparição em Fátima (1917), pedindo orações para a conversão da Rússia comunista (WERNET, 2007, p. 14). A Igreja colaborava para a construção de um imaginário coletivo em que o comunista se identificava com o demônio, símbolo do mal. Nesse cenário, só as iniciativas da Igreja seriam suficientes para combatê-lo. É mais um elemento sustentador das relações entre o governo varguista e a instituição eclesial, que se caracteriza, segundo Castro (2007, p. 23), por um regime de "concordata-moral", no qual a Igreja colabora na legitimação do governo e esse se empenha no combate aos inimigos hereges, que, além dos comunistas, incluem os protestantes, espíritas e judeus.

\section{Considerações finais}

Este artigo buscou evidenciar as congruências entre o pensamento eugênico e o pensamento católico principalmente em torno da defesa do ensino religioso nos discursos da Assembleia Constituinte de 1934. Verifica-se que o aperfeiçoamento moral é um ideal eugênico congruente com a grande pauta de regeneração moral da sociedade que interessa à Igreja.

O papel da religião católica, de forma institucional e pela influência cultural, foi para a conformação do movimento eugênico nos moldes que se viu no Brasil. De forma visível, o contexto das nações europeias, cujo desenvolvimento esteve associado ao eugenismo, era diferente do contexto socioeconômico no Brasil: país subdesenvolvido com população, em geral, católica, rural, racialmente mista e analfabeta. Além disso, era marcante no movimento integralista brasileiro uma orientação católica. Dessa forma, o eugenismo desenvolvido aqui foi adaptado, afastando-se dos extremos e 
voltando-se para um conteúdo mais higienista, o que o direcionou para o caminho da educação, fiscalização higiênica, políticas sanitaristas e controle sobre a família. Nesse contexto, a escola é vista como um espaço privilegiado para propagação de bons hábitos e ensino das doutrinas eugênicas. Pôde-se verificar que se a pauta eugênica logrou algum sucesso foi devido à afinidade de ideias com o conservadorismo católico.

A constituição de 1934 dará legalidade para ação estatal de aprimoramento eugênico da população, assim como estabelecerá o Plano Nacional de Educação, conduzido por lideranças católicas. A educação para todos é defendida não como um bem em si mesma, mas porque há necessidade de se investir tanto nos corpos quanto na consciência. O Estado, por sua vez, aproximava-se dos valores religiosos aceitos socialmente, penetrando nos vários grupos sociais de forma a garantir novas relações de poder, legitimando sua ação autoritária e centralizada que culminará no Estado Novo em 1937.

O foco do interesse eclesiástico na educação certamente iria além do ensino religioso, confirmando as denúncias apresentadas de que tal ensino era apenas o "primeiro passo" nas pretensões da Igreja. A educação escolar é entendida como a possibilidade de formar a alma do brasileiro, inculcando nele uma moralidade religiosa que salvaria a nação dos caminhos de infelicidade determinados pela laicização do ensino e da ameaça de expansão do comunismo no mundo.

Observa-se que a Igreja logrou importantes conquistas em seu projeto de retomar o espaço perdido com a República: as emendas religiosas são incorporadas à Constituição; Getúlio Vargas, em um ato de acatamento à autoridade da Igreja, se casa no religioso, após anos de vínculo estritamente civil; e Gustavo Capanema é empossado no Ministério da Educação e Saúde, após negociações das quais participou Alceu Amoroso Lima, ${ }^{20}$ que se transformaria, daí por diante, em mentor espiritual e intelectual do Ministro e de toda a atividade educacional no país.

No pós-34, a partir da relação entre Capanema e seu mentor, fica ainda mais clara a intenção da Igreja de que toda a educação do país deveria ser estruturada segundo princípios fundamentais da religião católica. ${ }^{21}$ De fato, mesmo após a era Vargas, o conservadorismo católico continuaria a manter

20 Alceu Amoroso Lima foi uma importante figura do laicato católico. Foi um dos auxiliares de Dom Sebastião Leme na formação da LEC. Exerceu grande influência na educação nacional, particularmente nos anos 30. Foi integrante do Conselho Nacional de Educação e do Conselho Federal de Educação de 1935 a 1969.

21 Sobre as relações entre Alceu Amoroso Lima e Gustavo Capanema na articulação do interesse católico e as políticas educacionais do governo Vargas, ver SCHWARTZMAN (1986), especialmente as partes IV e V. 
posições importantes no sistema educacional brasileiro por muitas décadas. Daí a importância dos estudos sobre políticas públicas educacionais que se voltam a esse período com o objetivo de fortalecer valores crucias para a democracia brasileira atualmente como laicidade, equidade e respeito aos direitos humanos.

\section{Referências Bibliográficas}

ANNAES da Assembléa Nacional Constituinte. Volume I ao XXII. Rio de Janeiro: Imprensa Nacional, 1936. Disponível na Biblioteca Digital do Congresso Nacional: <http:// bd.camara.gov.br/bd/handle/bdcamara/6>. Acesso em: 26 abr. 2018.

CASTRO, E. G. Os “Quebra-santos”: anticlericalismo e repressão pelo DEOPS/SP. São Paulo: Humanitas, 2007.

GHIRALDELLI JUNIOR, P. História da educação brasileira. 4. ed. São Paulo: Cortez, 2009.

GONDRA, J. G. Medicina, Higiene e educação escolar. In: LOPES, E. M. T., FARIA

FILHO, L. M. V., GREIVE, C. (Orgs.). 500 anos de educação no Brasil. 3. ed. Belo Horizonte: Autêntica, 2007. p. 519-550

OLIVEIRA, R.S. Para salvar a nação: uma teorização sobre educação, saúde e religião na Assembleia Constituinte de 1934. 2018. 235f. Tese (Doutorado em Educação) --Escola de Comunicação, Educação e Humanidades da Universidade Metodista de São Paulo, São Bernardo do Campo, 2018.

SCHWARTZMAN, S. A política da Igreja e a educação: o sentido de um pacto. Religião e Sociedade, Rio de Janeiro, vol. 13, n. 1, mar. 1986.

STEPAN, N.L. Eugenia no Brasil, 1917-1940. In: HOCHMAN, G., and ARMUS, D., orgs. Cuidar, controlar, curar: ensaios históricos sobre saúde e doença na América Latina e Caribe[online]. Rio de Janeiro: Editora FIOCRUZ, 2004. História e Saúde collection, p. 330-391. SciELO Books.

WERNET, A. Prefácio. In: CASTRO, E. G. Os “Quebra-santos": anticlericalismo e repressão pelo DEOPS/SP. São Paulo: Humanitas, 2007. p. 11-17.

Submetido em: 1-10-2018

Aceito em: 19-12-2018 